\title{
Perancangan Sistem Pakar Untuk Mengidentifikasi Gangguan Pada Tanaman Jambu Air Menggunakan Metode Certainty Factor
}

\author{
Ahmat Yusuf ${ }^{1}$, Bagus Satrio Waluyo Poetro ${ }^{2}$ \\ ${ }^{1}$ Universitas Islam Sultan Agung/Teknik Informatika \\ address : Jl. Kaligawe KM.4, email : ahmat@unissula.ac.id \\ 2Universitas Islam Sultan Agung/Teknik Informatika \\ address : Jl. Kaligawe KM.4 email : Bagusswp@Unissula.ac.id
}

\begin{abstract}
The state of Indonesia, especially in the area of Central Java, is one of the largest producers of water guava. Some farmers rely on the results of guava cultivation as the basis for the family's economy because the guava harvest is quite promising. However, in certain seasons, water guava plants are often attacked by various kinds of pest and disease season disturbances. So that it can reduce crop yields or even cause crop failure. To overcome this problem, fast and precise action is needed so that the guava plant is protected from various kinds of pests and diseases. The method of developing an expert system for disturbance in water guava plants is the best solution in order to identify disturbances in water guava plants as early as possible. The method used in this expert system is the certainty factor method. With this method, several experts are needed to provide data related to disturbances in water guava plants. The expert system for guava plant disorders is designed using a web-based PHP programming language. In designing the knowledge base, which is the core of this system, is made dynamically to make it easier to add new data.
\end{abstract}

Keywords: expert systems; certainly factor

This is an open access article under the CC BY license.

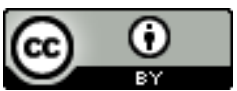

\section{INTRODUCTION}

Data dari Badan Pusat Statistik (BPS) Provinsi Jawa Tengah produksi jambu air mencapai sekitar 100.000 kuintal per tahun. Melalui data terakhir yang diambil oleh BPS Jateng tanggal 24 Februari 2017 pada empat tahun terakhir yakni 2012 hingga 2015 tingkat produktifitas jambu air belum menunjukkan tingkat kemajuan. Produktifitas Jambu air di Jawa Tengah masih fluktuatif karena masih banyak petani yang belum paham akan perawatan dan penanganan yang baik pada tanaman jambu air $[1,2,3]$.

Kabupaten Demak merupakan daerah komoditas perkebunan jambu air terbesar di Jawa Tengah. Dengan lokasi dataran yang rendah dan berada di pesisir pantai membuat daerah Kabupaten Demak sangat cocok ditanami tanaman jambu air. Akan tetapi, tanaman jambu air di daerah Demak sering terjangkit penyakit di antaranya adalah buah busuk, produksi buah jambu air tidak maksimal, bunga sering rontok dan lain-lain. Hal tersebut menimbulkan para petani jambu air merasa rugi dengan hasil panen yang belum maksimal $[1,4,5]$.

Tanaman jambu air rentan terhadap gangguan hama dan penyakit. Jika tidak ditangani segera akan mengakibatkan pertumbuhan yang kurang maksimal dan hasil produksi buah jambu akan menurun. Menurut Bapak Solikin sebagai ketua pertanian dan perkebunan di desa Wonokerto Kecamatan Karang Tengah Kabupaten Demak, masyarakat kesulitan dalam menangani gangguan pada tanaman jambu air dikarenakan kurangnya pemahaman dan pengetahuan tentang tanaman jambu air, Sehingga hasil produksi buah jambu air 
belum bisa maksimal. Banyak tanaman jambu air warga yang terserang hama dan penyakit, tetapi belum tahu solusi yang efektif untuk menanggulangi gangguan tersebut [6].

Sistem pakar (expert system) merupakan salah satu bidang pengembangan kecerdasan buatan (artifical inteligence). Dimana kecerdasan buatan adalah bagian dari ilmu komputer yang dibuat agar memiliki tingkah laku atau cara berfikir seperti manusia. Sistem pakar sangat efektif digunakan oleh seseorang yang membutuhkan solusi terbaik dari beberapa pilihan solusi. Dengan menggunakan sistem pakar untuk mengidentifikasi gangguan pada tanaman jambu air, para petani akan lebih cepat dalam mengambil tindakan untuk menanggulangi masalah pada tanaman mereka. Sehingga produktifitas buah jambu air dapat terjaga dan meningkat $[7,8]$.

Dari penjelasan di atas, maka peneliti tertarik untuk merancang dan membangun sebuah sistem pakar untuk mengidentifikasi gangguan pada tanaman jambu air berbasis web. Dengan tujuan untuk memberi informasi kepada para petani jambu air tentang macam-macam gangguan yang sering di alami oleh tanaman jambu air serta bagaiman cara mengatasinya dengan efektif berdasarkan pemikiran seorang pakar yang sudah berpengalaman di bidang perkebunan jambu air.

\section{LITERATURE REVIEW}

Metode Certainty Factor digunakan ketika menghadapi suatu masalah yang jawabannya tidak pasti. Ketidakpastian ini bisa merupakan probabilitas. Metode ini diperkenalkan oleh Shortlife Buchanan pada tahun 1970-an. Beliau menggunakan metode ini saat melakukan diagnosis dan terapi terhadap penyakit meningitis dan infeksi darah. Tim pengembang dari metode ini mencatat bahwa, dokter sering kali menganalisa informasi yang ada dengan ungkapan seperti "mungkin", "hampir pasti" [9, 10, 11, 12].

Berikut ini adalah rumus metode Certainty Factor :

$\mathrm{CF}[\mathrm{h}, \mathrm{e}]=\mathrm{MB}[\mathrm{h}, \mathrm{e}]-\mathrm{MD}[\mathrm{h}, \mathrm{e}]$

Keterangan :

$\mathrm{CF}[\mathrm{h}, \mathrm{e}] \quad=$ Faktor kepastian

$\mathrm{MB}[\mathrm{h}, \mathrm{e}]=$ Measure of belief, ukuran kepercayaan atau tingkat keyakinan terhadap hipotesis $(\mathrm{h})$, jika diberikan evidence (e) antara 0 dan 1.

$\mathrm{MD}[\mathrm{h}, \mathrm{e}] \quad=$ Measure of disbelief, ukuran ketidakpercayaan atau tingkat keyakinan terhadap hipotesis (h), jika diberikan evidence (e) antara 0 dan 1.

Adapun beberapa kombinasi Certainty Factor terhadap premis tertentu:

1. Certainty Factor dengan satu premis.

$\mathrm{CF}[\mathrm{h}, \mathrm{e}]=\mathrm{CF}[\mathrm{e}] * \mathrm{CF}[$ rule $]=\mathrm{CF}[$ user $] * \mathrm{CF}[$ pakar $]$

2. Certainty Factor dengan lebih dari satu premis.

$\mathrm{CF}[\mathrm{A} \wedge \mathrm{B}]=\mathrm{Min}(\mathrm{CF}[\mathrm{a}], \mathrm{CF}[\mathrm{b}]) * \mathrm{CF}[$ rule $]$

$\mathrm{CF}[\mathrm{A} \vee \mathrm{B}]=\operatorname{Max}(\mathrm{CF}[\mathrm{a}], \mathrm{CF}[\mathrm{b}]) * \mathrm{CF}[$ rule $]$

3. Certainty Factor dengan kesimpulan yang serupa.

$\mathrm{CF}$ gabungan $[\mathrm{CF} 1, \mathrm{CF} 2]=\mathrm{CF} 1+\mathrm{CF} 2 *(1-\mathrm{CF} 1)$

\section{RESEARCH METHOD}

Proses dalam pengembangan sistem ini menggunakan metode waterfall. Ada 4 tahapan pada metode waterfall yaitu analisa sistem, perancangan sistem (design), implementasi sistem (code) dan pengujian sistem (testing).

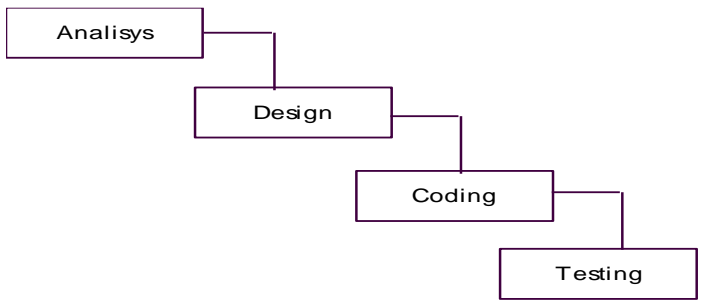

Gambar 3.1 Tahapan metode waterfall 
Sistem untuk mengidentifikasi gangguan pada tanaman jambu air merupakan salah satu sistem kecerdasan buatan khususnya sistem pakar, karena pemecahan masalah tersebut dapat dilakukan dengan mengembangkan sistem yang dapat berperan sebagai seorang pakar. Dengan kata lain terjadi pemindahan atau proses pengolahan informasi yang membangun dan mengoperasikan basis pengetahuan yang berisi fakta-fakta. Dalam hal ini merupakan proses penyerapan basis pengetahuan dari seorang pakar ke sebuah sistem computer. Fakta-fakta yang diperoleh dari seorang pakar disimpan dalam basis pengetahuan dan dengan bantuan mesin inferensi serta memori kerja maka proses penarikan kesimpulan tentang jenis gangguan pada tanaman jambu air dapat dilakukan. Berdasarkan kategori bidang yang sesuai, sistem pakar ini termasuk dalam jenis diagnosis, yaitu mencari ciri-ciri fisik atau gejala yang diderita oleh tanaman dan memberikan kesimpulan gangguannya beserta solusi mengatasinya $[13,14]$.

Diagram konteks pada sistem pakar ini terdapat dua entitas pengguna yaitu pakar dan user. Pakar akan melakukan login untuk masuk ke dalam menu pakar, kemudian pakar dapat mengolah data gejala, penyakit dan relasi. Sedangkan user dapat melakukan konsultasi pada menu yang sudah disediakan, kemudian akan mendapatkan hasil konsultasi berdasarkan fakta-fakta yang di inputkan. Berikut adalah gambar diagram konteks sistem pakar identifikasi gangguan tanaman jambu air ditunjukkan pada gambar 3.2.

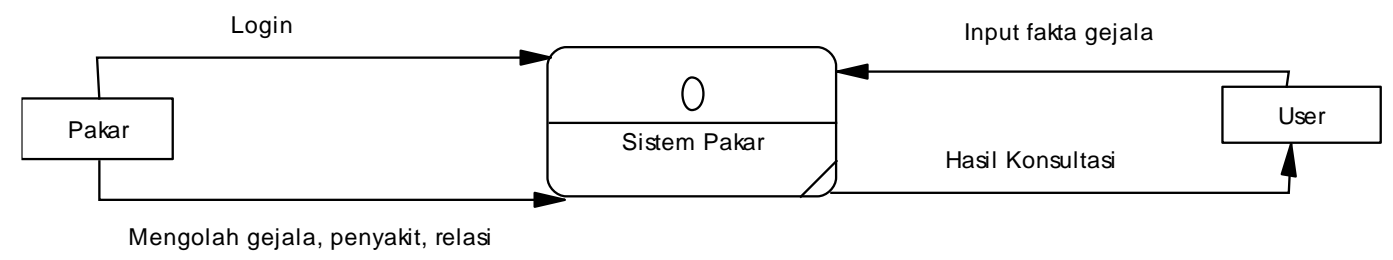

Gambar 3.2 Diagram Konteks

Data flow diagram level nol merupakan rincian dari diagram konteks. Dimana pakar melakukan login terlebih dahulu untuk masuk ke menu pakar, kemudian pakar dapat menginputkan data gejala dan disimpan dalam tabel gejala, data penyakit beserta solusinya dimasukkan ke dalam tabel penyakit serta membuat relasi Antara gejala dengan penyakit yang disimpan dalam tabel relasi. Selain menginputkan data, pakar juga dapat melakukan edit dan hapus data tersebut $[15,16]$.

Sedangkan user dapat langsung melakukan konsultasi mengenai gangguan pada tanaman jambu air dengan cara menginputkan fakta-fakta gejala yang dialami tanaman jambu air sebagai data inputan, kemudian user akan mendapatkan hasil konsultasinya [17, 18]. Berikut adalah gambar diagram DFD level nol pada sistem pakar identifikasi gangguan pada tanaman jambu air ditunjukkan pada gambar 3.3.

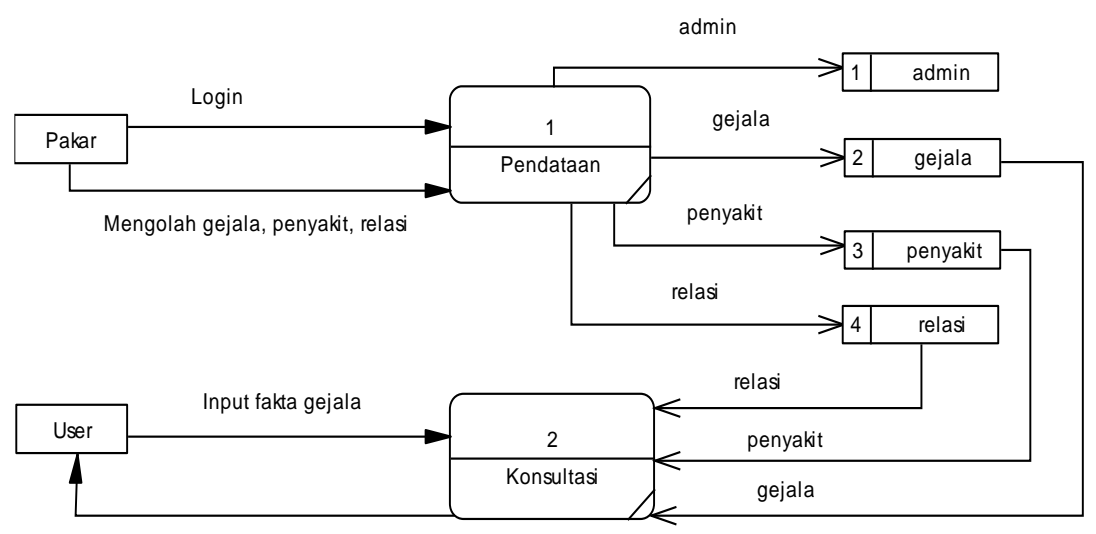

Hasil konsultasi

Gambar 3.3 DFD Level nol 


\section{RESULT AND ANALYSIST}

Hasil dari penelitian ini adalah sebuah sistem pakar menggunakan metode certainly factor

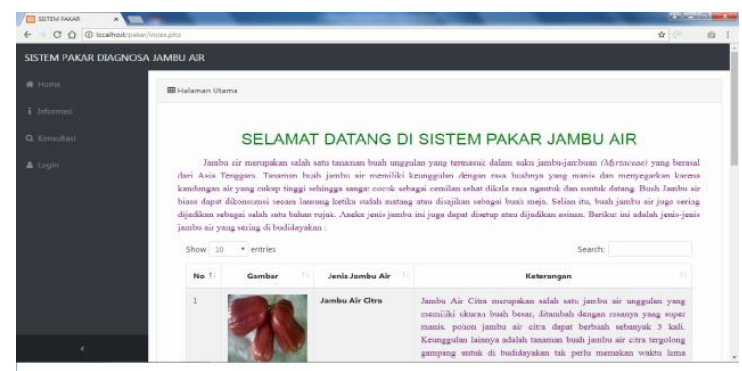

Gambar 4.1 Tampilan halaman home pengguna

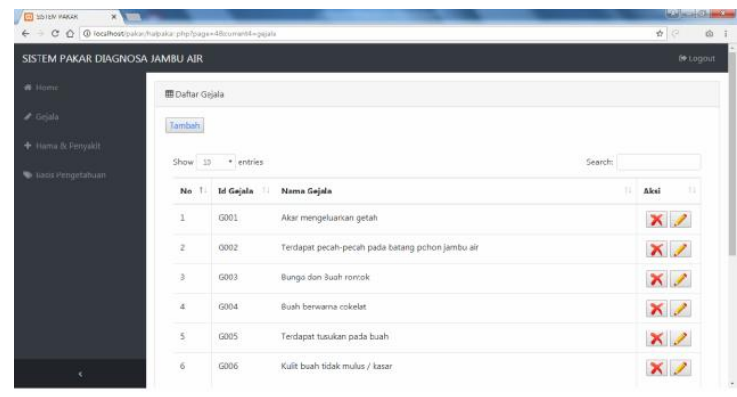

Gambar 4.2 Tampilan halaman gejala

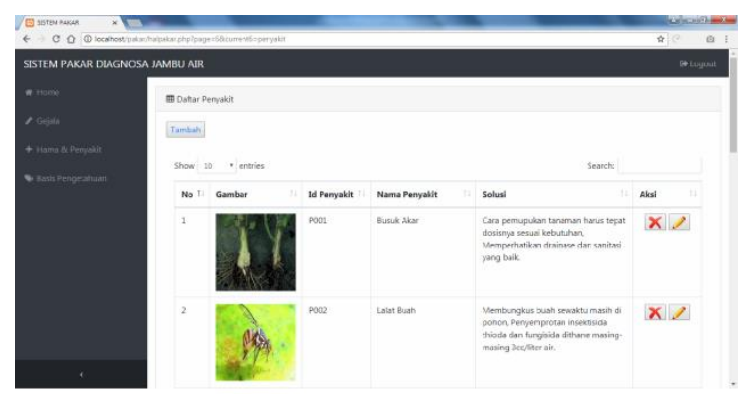

Gambar 54.3 Tampilan halaman penyakit

\section{CONCLUSION}

Dari uraian yang telah dijelaskan pada bab-bab di atas, maka dapat diambil kesimpulan dari sistem pakar identifikasi gangguan pada tanaman jambu air berbasis web adalah sebagai berikut :

1. Sistem pakar identifikasi gangguan tanaman jambu air dibuat dengan bahasa pemrograman $p h p$ berbasis web dan menghasilkan output sesuai dengan kebutuhan.

2. Sistem pakar identifikasi gangguan pada tanaman jambu air di rancang menggunakan metode Certainty Factor.

3. Sistem pakar identifikasi gangguan tanaman jambu air berbasis web dapat digunakan untuk menyelesaikan masalah diagnosis gangguan tanaman jambu air, karena telah di uji dan sesuai dengan perhitungan manual menggunakan metode Certainty Factor.

4. Sistem pakar identifikasi gangguan tanaman jambu air ini mempunyai kelebihan pada basis pengetahuan yang di rancang secara dinamis. Jika ditemukan gejala-gejala ataupun penyakit baru, maka dapat langsung ditambahkan kedalam sistem tanpa mengubah kode-kode dalam program. 
5. Tampilan hasil diagnosa penyakit telah ditambahkan gambar untuk memperjelas jenis hama atau penyakit yang menjadi kesimpulan utama diagnosa.

\section{REFERENCES}

[1] Abdullah, P. P. (2016) "Sistem Pakar untuk Mendiagnosa Penyakit pada Ayam dengan Metode Certainty Factor Berbasis Android."

[2] Anggrawati, P. S. dan Ramadhania, Z. M. (2016) "Kandungan Senyawa Kimia Dan Bioaktivitas Dari Jambu Air (Syzygium aqueum Burn. f. Alston)," 14, hal. 331-344.

[3] Arif, S. W. (2009) "Sistem Pakar Identifikasi Hama dan Penyakit Tanaman Apel Berbasis web."

[4] Desfandi dan Mirza Syiah (2015) "Mewujudkan Masyarakat Berkarakter Peduli Lingkungan Melalui Program Adiwiyata,” 2(1), hal. 31-37. doi: 10.15408/sd.v2i1.1661.

[5] Hidayat, A. (2015) "Pendidikan Islam dan Lingkungan Hidup," IV, hal. 373-389.

[6] https://jateng.bps.go.id/statictable/2017/02/24/1446/produksi-tanaman-buah---buahan-dansayuran-tahunan-jawa-tengah-2010-2015.html

[7] Irwan, N. (2016) "Aplikasi Sistem Pakar Identifikasi Penyakit pada Tanaman Padi Menggunakan Metode Certainty Factor."

[8] Kardoyo dan Nurkhin, A. (2011) "Perkembangan Jambu Demak Dalam Tinjauan Sejarah Dan Ekonomi," hal. 76-84.

[9] Kurniawan, I. (2012) "Rancang Bangun Sistem Pakar dalam Diagnosis Penyakit Telinga, Hidung dan Tenggorokan dengan Menggunakan Metode Certainty Factor."

[10] Kusumaningrum, A. W. (2013) "Sistem Pakar Diagnosa Penyakit Kulit pada Kucing dengan Metode Certainty Factor."

[11] Mauser, G. (2013) "Pembangunan Sistem Pakar Penanggulangan Hama dan Penyakit pada Tanaman Kentang Menggunakan Metode Certainty Factor."

[12] Nugroho, M. A. (2014) "Rancang Bangun Sistem Pakar untuk Penanganan Penyakit pada Durian Montong Berbasis Web."

[13] Pujiastuti, E. (2015) Jambu Air Eksklusif.

[14] Putri, M. (2016) "Sistem Pakar Penyakit Tanaman Kelapa Sawit dengan Metode Certainty Factor," hal. $1-19$.

[15] Rohajawati, S. dan Supriyati, R. (2010) "Sistem Pakar Diagnosis Penyakit Unggas pada Ayam," hal. 41-46.

[16] Siswanto (2000) Pengertian dan Sejarah Dari Artificial Intelligence(AI).

[17] Wilda, A. N. (2017) "Sistem Pakar Diagnosa Penyakit Tanaman Bawang Merah Menggunakan Metode Certainty Factor."

[18] Wirawan, I. M. A. (2017) Metode Penalaran dalam Kecerdasan Buatan. 